\title{
A successful reintroduction of European otters
}

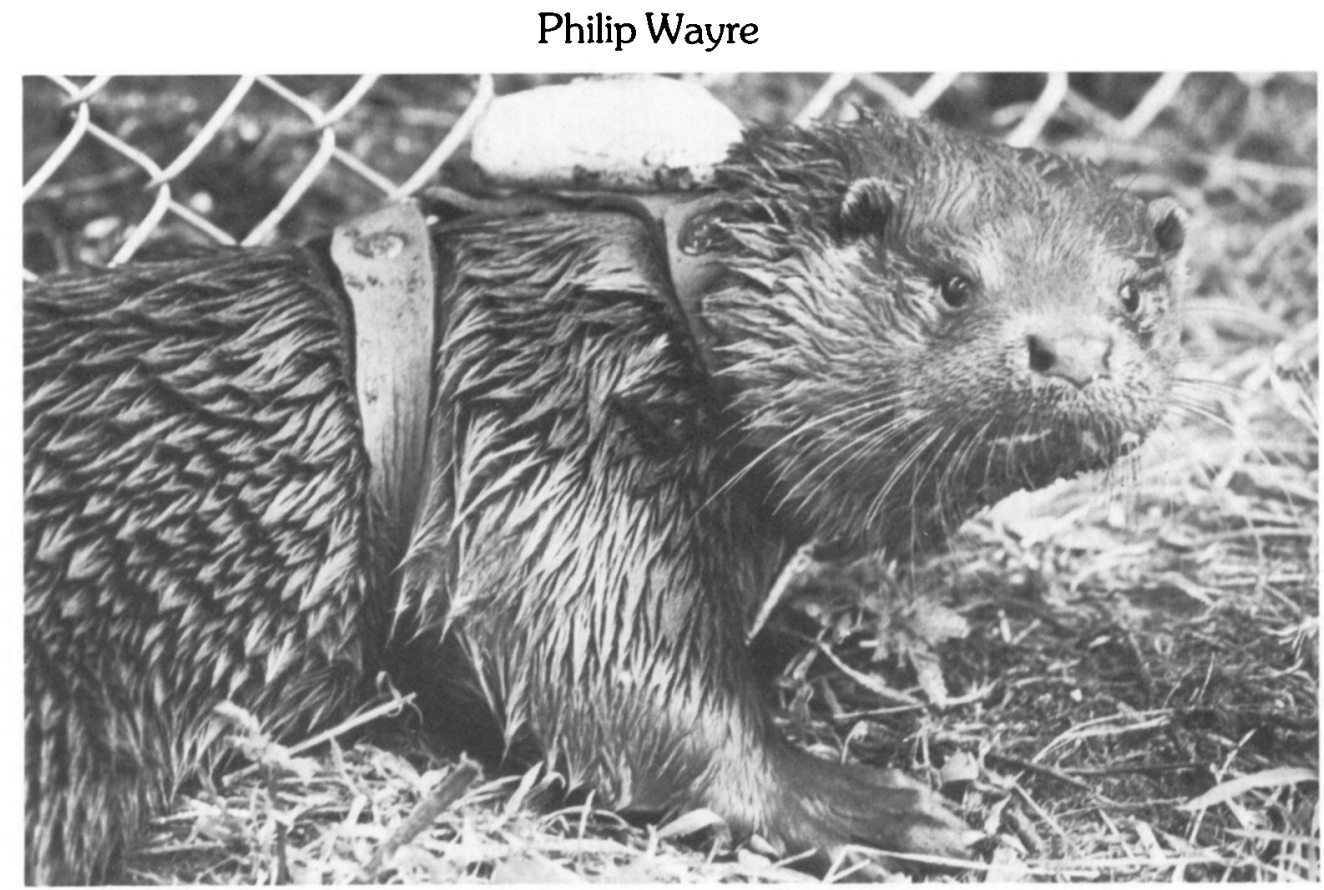

Male European otter, wearing harness with transmitter attached, shortly before release. The hamess is designed to disintegrate after a few weeks.

When the Otter Trust was set up in the UK in 1972 , one of its long-term intentions was to restore European otters to suitable wild habitat. In 1982, this aim came to fruition with the release of three captive-bred otters into a river in East Anglia. These otters have now bred in the wild and further releases continue to add to the success of the project. The author is Chairman of the Otter Trust.

Since the mid-1950s, the European otter Lutra l. lutra is known to have declined in numbers throughout most of England. The reasons for this decline have been discussed by Chanin and Successful reintroduction of European otters
Jefferies (1978). National and local surveys indicated that, in some areas, particularly in the Midlands and south-eastern England, the otter population had become fragmented into small pockets. It seemed likely that, in some instances, the population had become too small to be viable and capable of expanding into the existing gaps.

When the Otter Trust was founded in 1972, one of its principal aims was to breed the European otter in sufficient numbers in captivity to be able to make regular reintroductions into the wild where suitable habitat remained. However, it was not until 1983 that the stock of breeding otters at the Trust's headquarters at Earsham in Norfolk 
was considered large enough to warrant the return of young animals to the wild. The problems of such a reintroduction and the necessary preliminary research before release have been discussed in detail (Jefferies and Mitchell-Jones, 1982; Jefferies and Wayre, 1983). The area chosen for the release must satisfy certain criteria necessary for the otters' survival. These criteria and the release procedure have been discussed by Jefferies, Jessop and Mitchell-Jones (1984). There should be no otters in the area, although it is an advantage if adjacent areas still contain wild otters so that the reintroduced animals will, by filling the gap, link remaining wild populations. There must be sufficient cover, lack of disturbance, potential holt sites and few, if any, American mink Mustela vison. In addition, there should be a plentiful supply of coarse fish, including eels Anguilla anguilla. The water quality and pollution levels must be known to be satisfactory, and this entails the analysis of food fish to determine the levels of organochlorine insecticides, PCBs and heavy metals that would be passed on to the otters. These criteria mean, in effect, that only privately owned rivers are likely to provide suitable sites and, therefore, it is of the utmost importance that the riparian landowners and farmers should be made aware of any proposed release and be sympathetic to it.

The 1977-79 national survey (Lenton et al., 1980) showed that East Anglia had a fragmented otter population, which would lend itself to the reintroduction of captive-bred animals, and a survey of Norfolk carried out by the Otter Trust provided up-to-date information (Clayton and Jackson, 1981). As a result of research carried out by scientists from the Nature Conservancy Council (NCC) and from the Otter Trust, a small river on the border of Norfolk and Suffolk was chosen for the first pilot release. All the riparian owners likely to be affected by the scheme had been contacted by the Trust's Conservation Officer and all had shown themselves to be interested and extremely co-operative. A survey of the river was conducted by Dr D. J. Jefferies, Chief Scientist Team, NCC, and this included the dissection and analysis of five coarse fish to determine pollutant levels. In general, low levels of pollutants were discovered, and the levels of organochlorine insecticides found were much 138 lower than those occurring in coarse fish at the time of the otters' decline in the 1950s.

It was considered essential to gain as much information as possible on the success or otherwise of the first pilot release. To this end, scientists from the NCC had devised a special short-life radio harness, which was tested on captive animals at the Otter Trust and subsequently used for the tracking of wild otters by radiotelemetry (Mitchell-Jones et al., 1984).

It was decided for reasons discussed by Jefferies and Wayre (1983) to use young animals aged about 18 months old for the first release. This would avoid two periods of high mortality, the first when the animals become independent of the female, and the second during their first winter following independence. It also had the advantage of reducing the period before the animals would be old enough to breed. The three captive-bred otters (one male and two female) were kept for some months prior to the release in a large pre-release enclosure at the Otter Trust. Two such enclosures had been built outside the public area with the assistance of the World Wildlife Fund. While in these enclosures, the otters were disturbed as little as possible to lessen their chances of becoming tame. Owing to the amount of cover available, the otters were rarely seen, particularly as they soon became nocturnal in their habits. The ratio of two females and one male was chosen because it approximates to the situation found in the field in Britain where a mature male may have at least two breeding females within his home range (Green et al., 1984). Further, it was decided to release the animals as early as possible in the summer so that they would have every chance to leam to fend for themselves in the wild before facing the possibility of a severe winter.

A small release pen was built on an island within a few yards of the river bank. Two standard sleeping boxes with entrance tunnels, as used at the Otter Trust, were placed in the pen and the food trays were also covered by a tunnel to prevent wild birds from eating the food during the daytime. It was hoped that the otters would come to regard this enclosure as their base and would return to it at least during the early stages of their freedom; thus, it would be possible to continue

Oryx Vol 19 No 3 
feeding them until they had learned to catch their own quarry. Six days before their release, all the otters were anaesthetised by NCC scientists, examined and weighed, and the male was fitted with a harness with a radio transmitter and betalight for later use in the field.

At $20.00 \mathrm{hr}$ GMT on 5 July 1983 the pen door was opened, and at $21.10 \mathrm{hr}$ the fluctuation of the radio signal seemed to indicate that the male at least had left the pen. A continuous watch was kept during the first night until long after dawn, and this showed that the otters remained within $30 \mathrm{~m}$ of the pen, lying up in thick clumps of nettles Urtica dioica and under nearby willows Salix spp. on the island. Food in diminishing quantities was placed in the pen every day for the following 12 days. The animals returned to eat on several nights following their release, the last time being on the night of 11/12 July, after which they did not return to the pen. Regular monitoring of the animals' movements was carried out by Dr Don Jefferies and Dr Tony Mitchell-Jones of the NCC, and by Dr Rowena Jessop of the Otter Trust. In all, 185 hours were spent radio-tracking and monitoring their behaviour during 50 nights. The harness remained on the male otter for 50 days and was recovered by Dr Jessop on the night it fell off. During this time, the animals' home range had increased to approximately $15 \mathrm{~km}$ of river. Thereafter, tracking was continued by surveying for spraint under local bridges; this showed that after 100 days the range had extended to 31.5 $\mathrm{km}$. Continued monitoring showed that the animals had established themselves in the area of release and were behaving exactly like wild otters, being strictly nocturnal and extremely shy. There were no more sightings after the radio transmitter had been recovered, but the otters are known to be still in the area, including the immediate vicinity of the release pen, by their regular use of known sprainting sites and the frequent finding of their tracks.

For this first pilot release to be a complete success, it would have to result in the animals breeding successfully in the wild. On 14 August 1984, Dr Jessop, during one of her regular visits to monitor the area, found the tracks of a cub following those of an adult otter in the mud beneath a road bridge, proving beyond reasonable doubt that Successful reintroduction of European otters the released animals had bred successfully.

On 16 July 1984, three more otters (one male and two female) were released on another river in East Anglia following the procedure described above. Regular monitoring since that date has shown that these animals have also settled down in the release area and are behaving like wild otters. Two more young otters bred at the Trust were released at a third site in East Anglia during September 1984, and further releases are already underway.

\section{Acknowledgments}

The Otter Trust wishes to record its thanks to all those landowners and farmers, without whose sympathy and cooperation it would not have been possible to reintroduce young otters into the wild successfully. The Trust also wishes to record its gratitude to the NCC for their co-operation throughout the whole project and, in particular, to Dr Don Jefferies and Dr Tony Mitchell-Jones for their tireless efforts in the field, in the design of the radio-tracking harnesses and in all aspects of research leading up to the release itself. The work of co-ordinating the project, as well as much of the field work following the release, was carried out by the Trust's Conservation Officer, Dr Rowena Jessop, to whom the Trust owes its gratitude.

\section{References}

Chanin, P.R.F. and Jefferies, D.J. 1978. The decline of the otter Lutra lutra L. in Britain: an analysis of hunting records and discussion of causes. Biol. J. Linnean Soc. 10, 305328.

Clayton, C.J. and Jackson, M.J. 1981. Norfolk otter survey 1980-81. Otters, Joumal of the Otter Trust, 1980, 1622.

Green, J., Green, R. and Jefferies, D.J. 1984. A radio-tracking survey of otters Lutra lutra L. on a Perthshire river system. Lutra, 27, 85-145.

Jefferies, D.J., Jessop, R. and Mitchell-Jones, A.J. 1983. Re introduction of captive-bred European otters Lutra lutra, to suitable field stations in England. Otters, Joumal of the Otter Trust, 1983, 37-40.

Jefferies, D.J. and Mitchell-Jones, A.J. 1982. Preliminary research for a release programme for the European otter. Otters, Journal of the Otter Trust, 1981, 13-16.

Jeffries, D.J. and Wayre, P. 1983. Re-introduction to the wild of otters bred in captivity. Otters, Joumal of the Otter Trust, 1983, 20-22.

Lenton, E.J., Chanin, P.R.F. and Jefferies, D.J. 1980. Otter Survey of England, 1977-79. Nature Conservancy Council, London.

Mitchell-Jones, A.J., Jefferies, D.J., Twelves, J., Green, J. and Green, R. 1984. A practical system of tracking otters Lutro lutra using radiotelemetry and 65- $\mathrm{Zn}$. Lutra, 27, 71-84

Philip Wayre, The Otter Trust, Earsham, Nr Bungay, Suffolk NR35 2AF, UK. 